\section{PREVALENCE OF PSYCHOSOCIAL DISTRESS AMONG FLOOD VICTIMS IN SELECTED URBAN BARANGAYS IN PASAY CITY}

Bernadette Joy Quianio Almirol, Diana Francesca Galao Gepte, Czarina Charmaine Serdon Diwa, Ofelia Pardo Saniel. Department of Epidemiology and Biostatistics, College of Public Health UP Manila, Manila, Philippines

\subsection{6/bmjopen-2015-forum2015abstracts. 120}

Background This descriptive cross-sectional study was conducted in four urban barangays in the Maricaban-Malibay areas of Pasay City in NCR, Philippines. The residents of the study barangays were in their rehabilitation phase ${ }^{1}$ (i.e., three months post the simultaneous occurrence of Typhoon Maring and the Habagat) when the data collection was done.

Objectives To estimate the prevalence of psychosocial distress among the members of the community affected by wide-scale flooding.

Methods A sample of community residents aged 12-65 years old was selected using a stratified two-stage random cluster sampling method. $^{2}$ The presence of psychosocial distress was measured using the Self-Reporting Questionnaire-20 (SRQ-20), a screening tool developed by WHO. Some 506 accomplished questionnaires were returned to the investigators. The SRQ- $20^{3}$ has a sensitivity of $89.7 \%$ and a specificity of $95.2 \%$. Each of the 20 questions in this tool identifies the presence of a distressing symptom/indicator - those who scored 8 and above were considered positive for psychosocial distress. Principal Component Analysis (PCA) was used to group related indicators into one factor.

Result The prevalence of psychosocial distress in this population was estimated at $17 \%(95 \% \mathrm{CI}=13.7-20.3 \%)$. In the aftermath of the disaster, $46.8 \%$ of the respondents claimed to have experienced decreased energy, $49.8 \%$ had somatic symptoms, $25.9 \%$ had depressing thoughts and $40.9 \%$ experienced depressive moods.

Conclusion In times of disasters or other natural calamities, the psychosocial health of victims is usually overlooked in favour of more immediate concerns such as food and shelter. Flooding may directly cause or indirectly trigger the development of mental health problems among disaster victims who, to begin with, are usually poor and vulnerable to the risk of and the negative consequences of such disasters. ${ }^{4}$ Thus, it is important to consider the need for psychosocial interventions to affected populations in the aftermath of disasters.

\section{REFERENCES}

1 Boonyamalik P. Mental Health in Post-Disaster/Crisis: Systematic Approach. Thailand. Accessed 20 November 2013 from: http://www.imh.com.sg/uploadedFiles/Education/ Community_Training/Dr\%20Piktapol\%20Boonyamalik-Country\%20Presentation\%20 (Thailand).pdf; 23 September 2013. 
2 Centers for Disease Control and Prevention (CDC). Community Assessment for Public Health Emergency Response (CASPER) Toolkit: Second edition. Atlanta (GA): CDC; 2012.

3 World Health Organization. A User's Guide to the Self Reporting Questionnaire (SRQ). 1st ed. Geneva. World Health Organization; 1994.

4 UNISDR, UNDP. Disaster Risk Reduction and Climate Change Adaptation in the Pacific: An Institutional and Policy Analysis. Suva, Fiji: UNISDR, UNDP, 76pp 2012. 